\section{International Scientific Journal Theoretical \& Applied Science}

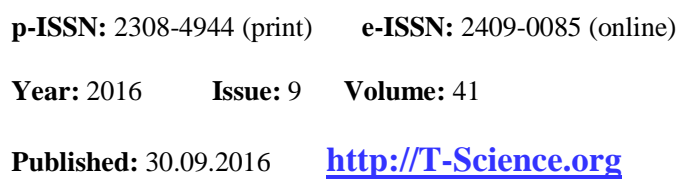

SECTION 31. Economic research, finance, innovation, risk management.
A.Sh.Kupeshev

Doctor of economical science, professor., Kazakh Engineering and Pedagogical University of Nations Friendship

V.Z.Erkebalaeva Candidate of economical science, docent, Kazakh Engineering and Pedagogical University of Nations Friendship

Aigul Kuanyshevna Kupesheva
Candidate of economical science
Chief of department of Kazakh
Engineering and Pedagogical
University of Nations Friendship

Ersultan Zhomartovich Shalkhar Muster student of Kazakh Engineering and Pedagogical University of Nations Friendship

Nurlan Muhtarovich Batyrbaev Candidate of law science, professor Vice president of International Kazakh-

Turkish University after H.A. Yessevi

Erkin Shazhievich Dusipov

Doctor of law science, professor Zhetysu state University after I.Zhansugurov

Yernar Sailaubekovich Shalkharov

Master of law, economics, bachelor of biology Corresponding member of Theoretical and Applied Science Academy. General director of BeinAgroIndustries LTD yernar_shalkharov@bk.ru

\title{
LEGAL PREREQUISITES IN CREATION OF THE CARABINIERE CADETS AND ITS ROLE IN QUESTIONS OF PRESERVING HISTORICAL AND CULTURAL HERITAGE OF THE REPUBLIC OF KAZAKHSTAN
}

Abstract: Now one of the most widespread questions is protection of cultural heritage worldwide. As a rule, many historical relics and artifacts are on the property right of other states, in many public funds, private collections and are on sale at auctions abroad. In the Republic of Kazakhstan there is no specific structure consisting of specialists of a narrow profile who could represent the interests of the republic on the international scene regarding protection of cultural heritage and control of export it from territory of the Republic of Kazakhstan.

Key words: Kazakhstan, cultural heritage, control.

Language: English

Citation: Kupeshev AS, Erkebalaeva VZ, Kupesheva AK, Shalkhar EZ, Batyrbaev NM, Dusipov ES, Shalkharov YS (2016) LEGAL PREREQUISITES IN CREATION OF THE CARABINIERE CADETS AND ITS ROLE IN QUESTIONS OF PRESERVING HISTORICAL AND CULTURAL HERITAGE OF THE REPUBLIC OF KAZAKHSTAN. ISJ Theoretical \& Applied Science, 09 (41): 153-155.

Soi: http://s-o-i.org/1.1/TAS-09-41-25 Doi: crossef http://dx.doi.org/10.15863/TAS.2016.09.41.25 


\section{Introduction}

This statement is expressed in the historical artifacts found in case of archeological excavations. At the same time it should be noted that legislatively in the Republic of Kazakhstan the main objective in the field of culture which in compliance with part 9 of article 4 of the law of the Republic of Kazakhstan "about culture" consists in an obstacle to illegal export and import, illegal transfer of competences of the owner to cultural values, taking measures to their return from any adverse possession (1) is outlined. However specific state bodies except divisions of the Ministry of Internal Affairs the having wide range of actions, but without necessary skills and knowledge in the field of archeology of history of bodies don't exist. So, the specific list of competences of authorized body is specified in article 7 of the same law, however in this legislation cases of a conflict of interest where more qualified legal preparation based on historical education (2) is necessary aren't specified. As this division creation of specialized international mediators in the field of archeology, differently would be very urgent as it is accepted to call on the example of many developed countries with rich historical and cultural heritage cases of carabineers (3).

\section{Materials and Methods}

Legally, this concept in the Republic of Kazakhstan is feasible and has rather large number of standard elements that definitely, shows rather high probability of success of implementation of this policy. Having rich historical roots, the territory of the Republic of Kazakhstan is integrated to various pieces of many historically significant events, and also the status of the Republic on the international scene assumes protection of many objects as heritage of UNESCO that is very positive factor in only the developing state (4). However maneuvering in the field of archaeological culture on the international scene allows not only to keep values, but also generates the conflict with many foreign subjects which owing to a long experience have great opportunities for withdrawal of many artifacts having huge cultural heritages for the Kazakh people as for example Keyki's batyr head or Taykazan's cover (5). The parties not only neighboring states, but also bodies of the large international organizations where it is necessary to work very thinly and delicately were net legally involved in both conflicts in case of interpretation regulation(6). On the one hand implementation of this policy by subjects of department of foreign affairs is a reasonable exit from situations; however owing to the restrictions on functional obligations subjects of diplomatic service have no sufficient power to perform many functions which are peculiar to experts (7).

Many manuscripts, artifacts, books, other printing audio-video records, stored in various storages, the museums, collections, libraries outside Kazakhstan weren't returned properly. And as dynamically developing state Republic of Kazakhstan has development of historical and cultural heritage as one of the key purposes. Unfortunately this fact is impossible without original artifacts. But, as well as it was mentioned above in the Republic of Kazakhstan there are enough standard elements for creation of service of universal independent mediators - the services of karabiners of the foreign languages having legal and historical education with knowledge basing the competences within the ratified international treaties, conventions and also internal Kazakhstan laws where on hierarchy of the legislation the Constitution of the Republic of Kazakhstan, Law of the Republic of Kazakhstan "About Protection and Use of Objects of Historical and Cultural Heritage" July 2, 1992 No. 1488-XII, and Law of the Republic of Kazakhstan "About culture" (8). This institute can have broad application not only for protection of historical values, but also regarding questions of regulation of the international legal relationship concerning fine arts objects, elements of ceramics, sculpture having special national color (9).

In many countries of service of karabiners belong to division of law-enforcement bodies, however taking into account specifics of the Republic of Kazakhstan as a post of the Soviet state it would be more reasonable to create this structure subordinated to bodies of the foreign cases (10). First because specifics of work is interaction with foreign departments subjects and coordination of the international activities within the ratified agreements. In the internal affairs bodies of the Republic of Kazakhstan there are no specialists with such skills as generally activities are connected with law and order (11). Secondly this structure shall is in jurisdiction of the Ministry of Foreign Affairs because it can adjust legal relationship with partners from foreign countries regarding improvement of the relations in scientific activities (12).

\section{Conclusion}

Thus, being dynamically developing state for achievement of certain heights the Republic of Kazakhstan shall take care of representatives of state interests, competent of representation, regarding protection of historical values. On service in karabiner tough candidate screen also shall be provided as shall be the main criteria the higher legal education, the higher historical education and knowledge of several languages at the upper intermediate level with Basic English level IELTS 7.

\section{Background}

For a whole competent it is actual to notice that all issues in articles were formulated from the surveys of BeinAgroIndustries LTD. Also, it is 
important to mention together work of two university staff: Kazakh Engineering and Pedagogical University of Nations Friendship and International
Kazakh-Turkish University after Khoga Akhmet Yassavi. In case of novelty, p.t.value the main author is the last in the list of authors.

\section{References:}

1. Stefan Lehner, Veit Senner (2013) Evaluation of Ergonomics of a New Effort Saving Viaferrata Carabiner-child vs. Adult Use. Original Research Article. Procedia Engineering, Volume 60, 2013, Pages 319-324.

2. Michael May, Stefan Furlan, Holger Mohrmann, Georg C. Ganzenmüller (2016) To replace or not to replace? - An investigation into the residual strength of damaged rock climbing safety equipment. Original Research Article. Engineering Failure Analysis, Volume 60, February 2016, Pages 9-19.

3. Spierings AB, Henkel O, Schmid M (2007) Water absorption and the effects of moisture on the dynamic properties of synthetic mountaineering ropes. Original Research Article. International Journal of Impact Engineering, Volume 34, Issue 2, February 2007, Pages 205-215.

4. Ken Zafren, Bruno Durrer, Jean-Pierre Herry, Hermann Brugger (2005) Lightning injuries: prevention and on-site treatment in mountains and remote areas: Official guidelines of the International Commission for Mountain Emergency Medicine and the Medical Commission of the International Mountaineering and Climbing Federation (ICAR and UIAA MEDCOM). Resuscitation, Volume 65, Issue 3, June 2005, Pages 369-372.

5. Jason W. Miesbauer, Edward F. Gilman, Forrest J. Masters, Sangam Nitesh (2014) Impact of branch reorientation on breaking stress in Liriodendron tulipifera L.. Original Research Article. Urban Forestry \& Urban Greening, Volume 13, Issue 3, 2014, Pages 526-533.

6. Arndt von Koeningsmarck (2008) Chapter 1 Short Projects. CINEMA 4D 11 Workshop, 2008, Pages 1-89.
7. Alexander Graf, Kai Yang, Kristen Klement, Nicholas Kim, Hani Matloub (2016) Abdominal suspension during massive panniculectomy: A novel technique and review of the literature. JPRAS Open, Volume 8, June 2016, Pages 2328.

8. Mark Minton, Yvonne Droms (2012) Exploration of Caves-Vertical Caving Techniques. Encyclopedia of Caves (Second Edition), 2012, Pages 314-320.

9. Francisco del Piñal, Francisco J. García-Bernal, Julio Delgado, Marcos Sanmartín, Javier Regalado, Luis Cerezal (2006) Correction of Malunited Intra-Articular Distal Radius Fractures With an Inside-Out Osteotomy Technique. The Journal of Hand Surgery, Volume 31, Issue 6, July 2006, Pages 1029-1034.

10. Kristopher Kimmell, Vinay K. Pulusu, Kersi J. Bharucha, Elliott D. Ross (2015) Postural instability in Parkinson Disease: To step or not to step. Original Research Article. Journal of the Neurological Sciences, Volume 357, Issues 1-2, 15 October 2015, Pages 146-151.

11. Volker R. Schöffl, Georg Hoffmann, Thomas Küpper (2013) Acute Injury Risk and Severity in Indoor Climbing-A Prospective Analysis of 515,337 Indoor Climbing Wall Visits in 5 Years. Original Research Article. Wilderness \& Environmental Medicine, Volume 24, Issue 3, September 2013, Pages 187-194.

12. Rinat Kehat, Dean J. Bonsall (2009) Recurrent corneal metallic foreign bodies in children with autism spectrum disorders. Journal of American Association for Pediatric Ophthalmology and Strabismus, Volume 13. Issue 6, December 2009, Pages 621-622. 